\title{
Mass-customisation and self-reflective frameworks: early developments in New Zealand
}

\author{
John Clayton* \\ Emerging Technologies Centre, Waikato Institute of Technology, Hamilton, NZ
}

(Received 5 March 2012; final version received 1 June 2012)

\begin{abstract}
Education has long been regarded as the foundation stone of national growth and international competitiveness. In the last three decades national educational reforms to improve access to higher education qualifications, individual higher education institutions' aggressive national and international marketing initiatives and improved information and communication technology (ICT) systems and infrastructure have resulted in greatly increased participation in tertiary education. As a consequence of this wider participation, tertiary educators are now engaging with increased numbers of culturally and economically diverse learners in distributed ICT environments that they, the educators and learners, are often unfamiliar with. There is an expectation that these educators will be able to design learning modules to meet students' multi-cultural needs, in a range of contexts, with no additional resources. In essence, it is expected that learners will participate in individually customised learning events at a cost similar to traditional delivery. This requires a fundamental shift in educators and learners conceptions on the provision of education. The purpose of this paper is to explore how the development and deployment of reflective frameworks, based on recognised international standards, can fully engage learners in mass-customised environments. First this article outlines the key building blocks required for reflective mass-customisation to occur. Second, it illustrates how this concept is being tentatively explored at a New Zealand institution. Finally, it recommends the areas of action for further research on the impact and effect of masscustomisation on learners, educators and institutions to be undertaken.
\end{abstract}

Keywords: customisation; frameworks; self-reflection; New Zealand; assessment

\section{Context}

Driven by fiscal restraints and the need to remain globally competitive and internationally relevant in an increasingly networked world, national governments and individual institutions have introduced a number of educational reforms (New Zealand Ministry of Education 2010). In general these initiatives have focused on, firstly, improving performance and efficiency ensuring more learners, national and international, from a broader ethnic, cultural, economic and educational background can complete higher qualifications at an affordable or competitive cost (Clayton 2011). Secondly, they have focused on increasing the organisational integration of e-learning systems and information and communication technology (ICT) applications for administrative purposes and teaching and learning, enabling institutions to deliver educational activities to distributed sites nationally and internationally

*Corresponding author. Email: john.clayton@wintec.ac.nz 


\section{J. Clayton}

(Martinez 2011). As a consequence of these changes educational institutions have broadened entry criteria and aggressively marketed course offerings both within their own countries and externally (Barboza 2011). These actions have resulted in greatly increased enrolments from both domestic and international markets. Educators are now engaged with increased numbers of culturally diverse learners in environments that often discourage group and/or individual personal tuition. Learners and educators also need to acquire ICT skills and master software applications they were previously unfamiliar with (OECD 2005). If not well designed these reformdriven environments may encourage an approach where the impact of learning events is limited to the reproduction of knowledge rather than promotion of understanding (Mimirinis and Bhattacharya 2007).

These initiatives and reforms have seen a fundamental shift in the role of educators and learners and their conceptions of the provision of educational courses. Educators are required to balance the competing notions of individualised learning and mass-delivery to increasingly large, distributed, groups. In essence educators are challenged to deliver learning events to meet ever increasing numbers (mass-delivery) yet design these events to meet individualised learning preferences (customisation). For the purpose of this paper the design and delivery of personalised learning events for unlimited numbers is mass-customisation.

\section{Mass-customisation overview}

For the last two decades the limitations of traditional high-volume manufacturing practices have been exposed. The two bedrocks of this process-led mass production model, efficient pricing and product quality, providing firms with a competitive advantage, are being eroded. Rapid development of product, expanded product choice, limited shelf-life and increasing consumer demand for individualised goods and services and responsive delivery systems have seen a fundamental shift in organisational behaviour. Firms are increasingly adopting customer-centric operational practices such as mass-customisation (Cohen and Pine 2007). Whilst it has been argued that it is difficult to provide and all-encompassing definition of masscustomisation, there is common agreement that it is a customer-initiated process to which providers respond (Turner 2009). Under the production philosophy of masscustomisation, goods and services are produced to meet an individual customer's requirements with mass production efficiency. In essence consumers consume a service or product customised to their own specifications at a cost similar to pre-made, "off-the-shelf", generic products or services (Xia and Wang 2010). The challenge for producers is to acquire the agility and flexibility to customise products and/or services of excellent quality, in high volumes at a reasonable cost. Firms are meeting this challenge by pre-fabricating standardised components in high-volume while achieving customisation through customer-specific assembly and/or arrangement of these components (Verdouw et al. 2010). In this approach, where the final product and/or service is assembled from an existing inventory of standardised components, there is an assumption that sufficient components with the right functionality are readily available to be rapidly configured to meet consumer demand (Verdouw et al. 2010). This particular mass-customisation approach requires a robust and reliable, yet constrained, communication and design platform on which the customer can configure, and reconfigure, the product or service required until they are satisfied with the final outcome. This is normally accomplished by using 
information technology-facilitated interactive forms, labelled configurators, that are personal and user friendly (Cross et al. 2009). In mass-customisation the service to the client, not the creation of the product, becomes the focus of the production process.

\subsection{Mass-customisation in education}

In a traditional classroom environment learners are bound by time, place and pace. Learning activities are scheduled to occur in a specified room and an educator systematically guides learners to achieve stated objectives through a variety of teaching methods and learning events (Syed-Khuzzan and Goulding 2009). E-Learning environments are not as constrained as these traditional environments. Learners have more choice in the time they learn and the place the learning will occur. While instructors have carefully structured digital content and designed e-learning events to achieve identified objectives, the ultimate responsibility of achieving those outcomes is transferred from the instructor to the learner. In these more personalised environments, learners need to be more self-motivated and self-directed (Clayton 2009). Advances in information and communication technologies and digital databases have encouraged educators to further personalise these learning environments and apply increasingly sophisticated communication technologies and databases in the design of intelligent tutoring and testing systems. In these systems learner progression can be controlled and, if required, review and remediation interventions can be organised. The data collected during these training sessions can be used to identify future training requirements (Hwang, Tseng, and Hwang 2008). A technical example of this automation of learning is the European learning grid infrastructure (ELeGI) approach to formal learning. The ELeGI approach is based upon personalised knowledge construction using experiential-based and collaborative learning approaches situated in a personalised networked environment. Formal learning experiences are based on the automatic generation, a unit of learning (UoL) that dynamically adapts the learning process based upon the participants' behaviour within the environment (Gaeta, Gaeta, and Ritrovato 2009). An educationally focused example is the construction of a personalised learning environment prototype for the construction industry in the UK. The prototype is based on the assumptions that learners have different levels of motivation, different attitudes about teaching, different approaches to learning, and will react differently to specific learning environments or instructional practices. By using a diagnostic questionnaire, and an in-depth understanding of instructional design theories and pedagogical approaches, a learning environment meeting the learning styles of individual participants is created (Syed-Khuzzan, Goulding, and Underwood 2008). In essence it is argued that e-learning can provide the platform to customise learning for the individual.

\subsection{A model for mass-customised e-learning environments}

The design of personalised e-learning environments, involving multiple stake holders with multiple points of view of learning, is a complex task. These environments need to be built upon three divergent schools of thought: behaviourist, cognitive and constructivist (Peter, Bacon, and Dastbaz 2010). Behaviourists argue that learning occurs as a response to stimuli. Positive stimuli will result in learners repeating behaviour; negative stimuli will discourage a repeat of the behaviour. Cognitivists 


\section{J. Clayton}

argue that learning is a process. To fully engage learners we need to understand an individual's learning style and match teaching methods and content to this style. Constructivists argue that learning is constructed through reflection and interaction. To constructivists, learning occurs as individuals reflect on their current knowledge and interact with the physical and social environment created for learning (Clayton 2009). Therefore, any e-environment platform implemented needs to be agile. Agility means that the infrastructure created is sufficiently flexible to be quickly adapted to meet the technical requirements and teaching and learning approaches of all schools of thought (Syed-Khuzzan and Goulding 2009). In the literature there appears to be general agreement that the development of these agile platforms is based on three fundamental building blocks (Gaeta et al. 2009; Hwang et al. 2008; Syed-Khuzzan et al. 2008).

(1) Firstly, the learner interacts with the environment through an intuitive user interface. The interface is interactive and obtains from the learner background information on current capabilities, learning style preferences and identifies user requirements.

(2) Secondly, the structured data gathered in step one interact with distinct databases, such as learner profile, teaching approach, knowledge repository and assessment rubrics) to create personalised learning plans (PLP) designed to meet the students' learning style preference and identified requirements.

(3) The PLP is delivered, at the appropriate level; to the learner in an environment they are comfortable and competent in.

A schematic diagram of this process is illustrated in Figure 1.

\section{Building blocks of mass-customisation}

The concept of self-reflection (the conscious act of purposefully thinking about activities undertaken) has been widely debated in educational circles for a number of decades (Korthagen and Vasalos 2005). To advocates of reflective practice, deep learning is dependent on individuals making meaning from their experiences through the process of reflection. The outcomes of the reflective process help individuals, firstly, to highlight the strengths of their current skill and knowledge and, secondly,

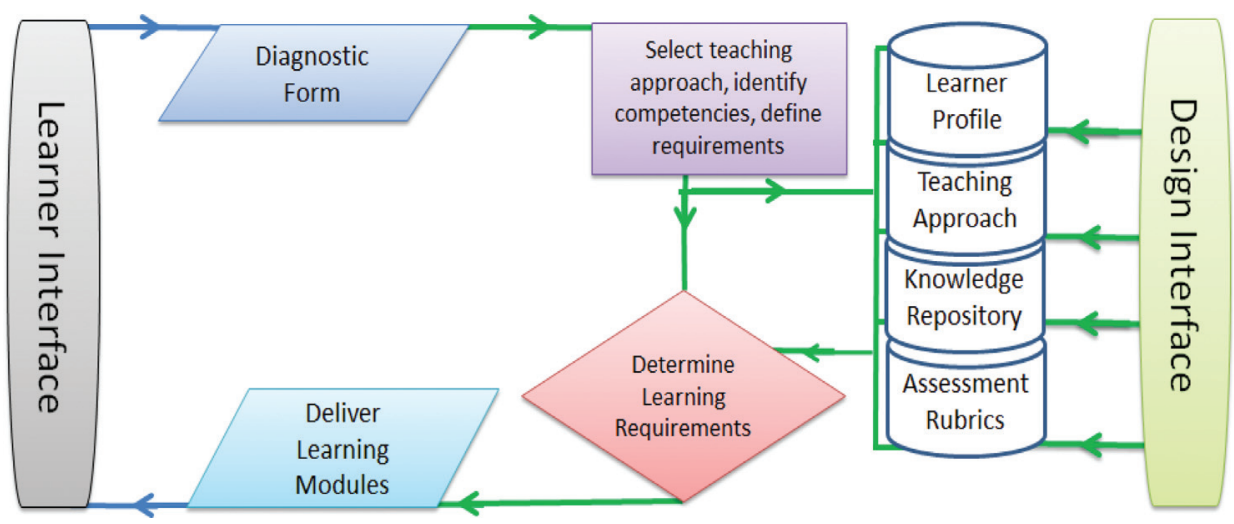

Figure 1. Conceptual overview of constructing personalised e-learning environments. 
identify areas where undertaking educational activities or training would facilitate increased capability. It is argued that this on-going reflection helps individuals iteratively build their capability and capacity (Carlson and Parry 2003; Clayton, Elliott, and Saravani 2009). In essence, reflection creates individualised learning environments that are on-going (sustained), connected to their needs (situated) and focused on individually generated tasks (authentic).

\subsection{Self-reflective frameworks}

A fundamental criterion for the success of reflection is the ability of the individual to make the appropriate connections between their existing skills, knowledge and experience and industry expected skill, knowledge and behaviours. If the learner has limited workplace experience, or limited exposure to other colleagues, their capacity to make informed judgements on their current competencies will be limited (Clayton 2011). To address this barrier, to engage participants in the self-reflective process and to aid them in making connections between their previous experiences and professional practices, self-reflective frameworks, based on acceptable standards and detailed in assessment rubrics, have been developed (Clayton 2011).

Fundamentally, these assessment rubric based self-reflective frameworks are designed to help individuals, with limited experience, or limited exposure to, or engagement with, other workers or colleagues, to make connections and comparisons between their existing skills and knowledge and industry-accepted best practice. This comparative process, using industry accepted standards, enables the individual, no matter their location, culture or language, to identify which competencies they are considered to be proficient in and those competencies they need to develop. The result of this reflective process is the generation of industry-grounded PLPs enabling them to become self-regulated learners (Zimmerman 1990).

\subsection{Assessment rubrics}

In educational settings it is generally agreed that assessments should be reliable (measurements of the same skills or knowledge produce the same results), consistent (all skills and knowledge are evaluated by identical procedures) and transparent (assessors and learners all share the same levels of expectation) (Latimer, Bergee, and Cohen 2010). Increasingly carefully designed assessment rubrics are being used to ensure reliability, consistency and transparency. At a fundamental level a rubric is an instrument that defines the requirements for a specified standard by dividing that standard into performance criteria and providing a description of what constitutes the level of performance for each of those individual criteria (Ciorba and Smith 2009). At this level the rubric serves to clarify expectations about individual student's level of performance. The agreed criteria and associated descriptions provided learners and educators with consistent standards to achieve within the course (Kerby and Romine 2010). At a more sophisticated level rubrics can radically alter institutions as the very act of developing and implementing rubrics forever alters perceptions of educators and administrators of student learning and assessment. These altered perceptions can create an educational culture that is transformed from one that is teaching-focused to one that is more learner-centred (Kieke, Moroz, and Gort 2007). In the creation of rubrics a number of developers use statements to define the standard and Likert scales to solicit responses. In the development cycle 


\section{J. Clayton}

of these rubrics an inclusive set of items describing identified aspects of a specific skill, competence or level of knowledge in a given discipline are created. These items then are paired with Likert-type, categorical response scales and assessors use these scales to record student achievement against the specified description (Ciorba and Smith 2009). Critically, the feedback provided by these rubrics empowers students to reflect on their current performance and identify weaknesses and strengths. This means that they can direct future efforts to identified areas of improvement. The feedback also allows educators to revise information provided, assignments set and instructional approaches used (Kerby and Romine 2010). In essence well-designed and implemented assessment rubrics could enable the personalisation of learning.

\subsection{Mentors}

It could be argued that the focus on standards-based, rubric driven criteria as the foundation of reflective frameworks acts as a constraint in the reflective process; it could restrict the acquisition of additional skills and knowledge and rigidly prescribe limited learning events (Strudler 2011). These valid concerns can be addressed by the appointment of an experienced mentor. The term mentor originates from Greek mythology when the well-travelled, and absent parent, Odysseus entrusted the care and education of his child to his friend called Mentor (Penner 2001). Traditionally, in business and industry, mentoring strategies are used to attract, retain and promote employees, ultimately improving individual and corporate performance and effectiveness. In the compulsory education and health sectors mentoring has long been acknowledged an integral part of professional learning and development. For example, in teacher education and nursing practicums, student teachers and nurses learn skills and techniques from either experienced classroom teachers or registered nurses. In the first years of their profession newly qualified teachers learn professional skills and strategies from experienced colleagues (Ghaye 2011). In higher education, while it has not always been easy for staff themselves to access it, mentoring has long been regarded as an important adjunct to teaching and learning (Strudler 2011). Through sustained feedback and follow-up, mentors create environments that encourage greater autonomy, personal transformation and deeper self-reflection. As such mentors should be regarded as a critical aspect of the selfreflective process.

\subsection{Portfolios}

Historically speaking, in artistic circles, portfolios not only summarised an artist's creative achievements, but they also illustrated those achievements in a physical form. As portfolios encourage the accumulation of physical evidence to illustrate achievement, they are seen to be a valuable tool for the formal assessment of competencies and are used in many professions such as nursing, medicine and teaching (McColgan and Blackwood 2009). Similarly, in formal accreditation environments, systematically compiled digital portfolios provide a protected shared space where learner evidence of competencies can be rigorously controlled and systematically evaluated (Fiedler, Mullen, and Finnegan 2009). Portfolios can be regarded as the purposeful collection of a learner's work structured to exhibit and illustrate the learners' efforts and achievements over time (Kim, Ng, and Lim 2010). Portfolios should be viewed as a personal learning management tool encouraging individual improvement, personal 
growth and development, and a commitment to life-long learning by encouraging on-going reflection.

\subsection{Mass-customisation and reflective frameworks}

Using the four building blocks outlined above (reflective frameworks, assessment rubrics, mentors and portfolios), a model for the customisation of learning, part human and part automated, can be produced. This process model involves four identified "actors", learners, mentors, designers and assessors, who engage with each other in a common virtual space. How these four actors interact with each other is described below.

(1) Firstly, the learner engages with the environment through an intuitive user interface. The interface uses an interactive self-reflective questionnaire, based on a discipline-specific assessment rubric, to gather data on the learners' current capabilities and existing knowledge.

(2) Secondly, the data gathered from the self-reflective questionnaire is firstly sent to a mentor appointed to facilitate learner progression to identified goals and secondly aligned with industry-accepted standards and gaps in learners' current competencies - and industry-accepted standards are automatically identified.

(3) Thirdly, the gaps identified between the learners' current knowledge and industry requirements are used as filters to interact with a complex learning object database (containing all learning activities to meet standards identified), to automatically generate a customised learning module. This learning module is delivered to the learner for action and to the mentor for information.

(4) Fourthly, the learner (in their own time, at their own pace and in a place of their own choice) works through the individualised learning module and simultaneously creates evidence to demonstrate their newly acquired competencies. During this stage of the process the learners, guided by their mentor, provide evidence of their previously stated capabilities and knowledge. All the evidence generated is systematically stored in a structured digital portfolio with categories aligned to an identified assessment rubric.

(5) Finally, when the learner and mentor agree that the evidence gathered meets all requirements of the assessment rubric, the portfolio is sent to an independent assessor. The independent assessor reviews the evidence presented and once more aligns this evidence with the assessment rubric. The assessor's judgement is then passed onto the learner.

A schematic diagram of this engagement and interaction is illustrated in Figure 2.

\section{Mass-customised courses: a New Zealand example}

In 2010 the Waikato Institute of Technology recognised the need to provide professional development (PD) in ICT for staff to meet the needs of its increasingly culturally diverse and technologically experienced student population. The certificate in open, flexible and networked learning (COFNL) consists of 5 modules based on identifiable Unit Standards registered with the New Zealand Qualification Authority 


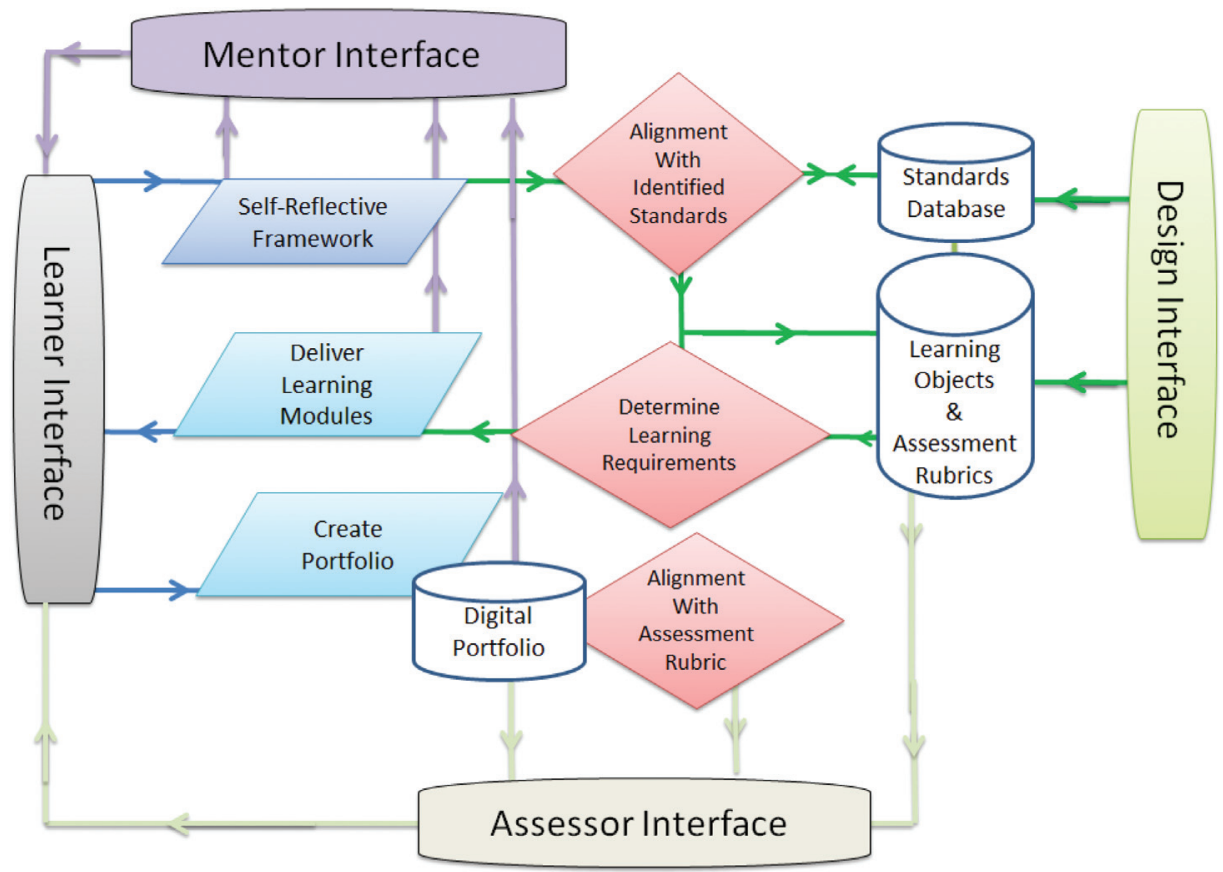

Figure 2. Conceptual model of mass customised learning module delivery.

(NZQA). Basing the modules on these registered standards ensured that the institute was following best national practice, and it aligned institutional PD delivery with national goals.

\subsection{The CAT: a reflective practice framework}

As noted previously the concept of reflection and that deep learning occurs as individuals make meaning from their experiences through reflection have been widely debated in educational circles for a number of decades (Ghaye 2011). To engage participants in reflective practice and to aid them in making connections between identified pedagogical standards in ICT and their previous experiences, a selfreflective competency assessment tool (The CAT) was created for COFNL learners. The CAT was designed to enable learners to assess their current competencies against nationally defined standards. The CAT interface provides the learner with a series of statements relating to each of the five modules within the COFNL. The statements within each module are classified within three categories, understanding, evidence and moderation.

- Understanding: This category prompts the learner to reflect on their personal knowledge of the aspect being investigated.

- Evidence: This category asks the learner if they can provide evidence of their understanding.

- Moderation: This category asks the learner how the evidence provided has been evaluated. 


\begin{tabular}{|c|c|}
\hline \multicolumn{2}{|l|}{ Understanding } \\
\hline $\begin{array}{l}\text { I have a good understanding of the relationships (such as direct, indirect, active, passive, interactive, } \\
\text { independent, and interdependent) that exist in open, flexible and networked learning environments. }\end{array}$ & Partially agree \\
\hline $\begin{array}{l}\text { I have evaluated the impact different relationships between participants in OFNL (such as direct, } \\
\text { indirect, active, passive, interactive, independent, and interdependent) have on student learning in } \\
\text { different contexts. }\end{array}$ & Strongly agree \\
\hline \multicolumn{2}{|l|}{ Evidence } \\
\hline $\begin{array}{l}\text { I can provide digital evidence of my understanding of the relationships (such as direct, indirect, active, } \\
\text { passive, interactive, independent, and interdependent) in open, flexible and networked learning } \\
\text { environments. }\end{array}$ & \\
\hline $\begin{array}{l}\text { I can provide digital evidence of how my understanding of the relationships between participants in } \\
\text { OFNL (such as direct, indirect, active, passive, interactive, independent, and interdependent) has been } \\
\text { used in my practice in different contexts. }\end{array}$ & Agree \\
\hline Moderation & \\
\hline $\begin{array}{l}\text { My understanding of the relationships (such as direct, indirect, active, passive, interactive, independent, } \\
\text { and interdependent) in open, flexible and networked learning environments has been peer reviewed. }\end{array}$ & Select \\
\hline $\begin{array}{l}\text { Practical application of my understanding of the relationships between participants in OFNL (such as } \\
\text { direct, indirect, active, passive, interactive, independent, and interdependent) has been peer reviewed } \\
\text { and assessed. }\end{array}$ & Select \\
\hline
\end{tabular}

Figure 3. Categories, statements and responses.

Learners are asked to reflect upon and then respond to individual statements using a "drop-down" menu. Categories, statements and example responses are illustrated in Figure 3.

As learners progress through the CAT, their answers affect the indicator colour on the index page. The indicator colours are based on the familiar "traffic light" theme:

- Red: This indicates to the learner that they have limited knowledge and/or experience of the identified standards. It also indicates how these limitations can be addressed.

- Yellow: This indicates that the learner has some knowledge and/or experience of the identified standard. It also indicates how this existing knowledge/ experience can be built upon.

- Green: This indicates to the learner that they meet the requirements of the identified standard. It also indicates to the learner that they can now build knowledge and experience in other areas.

As the learners progress through the modules, categories and statements, their responses provide a pictorial reflective framework carpet. This reflective process and visual carpet enable individuals to select which module(s) they need to review, which competencies they need to develop, what evidence they need to provide and how they should evaluate their practice.

The visual carpet produced from learner engagement provides the learner with:

- An initial assessment of their current knowledge, experience and understanding of individual aspects of this domain.

- An indication of potential starting points to begin a learning journey and

- Navigational tips to map a learning route from starting points to intended achievements.

In essence engaging with The CAT assists the learner in the creation of a PLP empowering them to become self-regulated learners.

This reflective visual carpet is illustrated in Figure 4. 


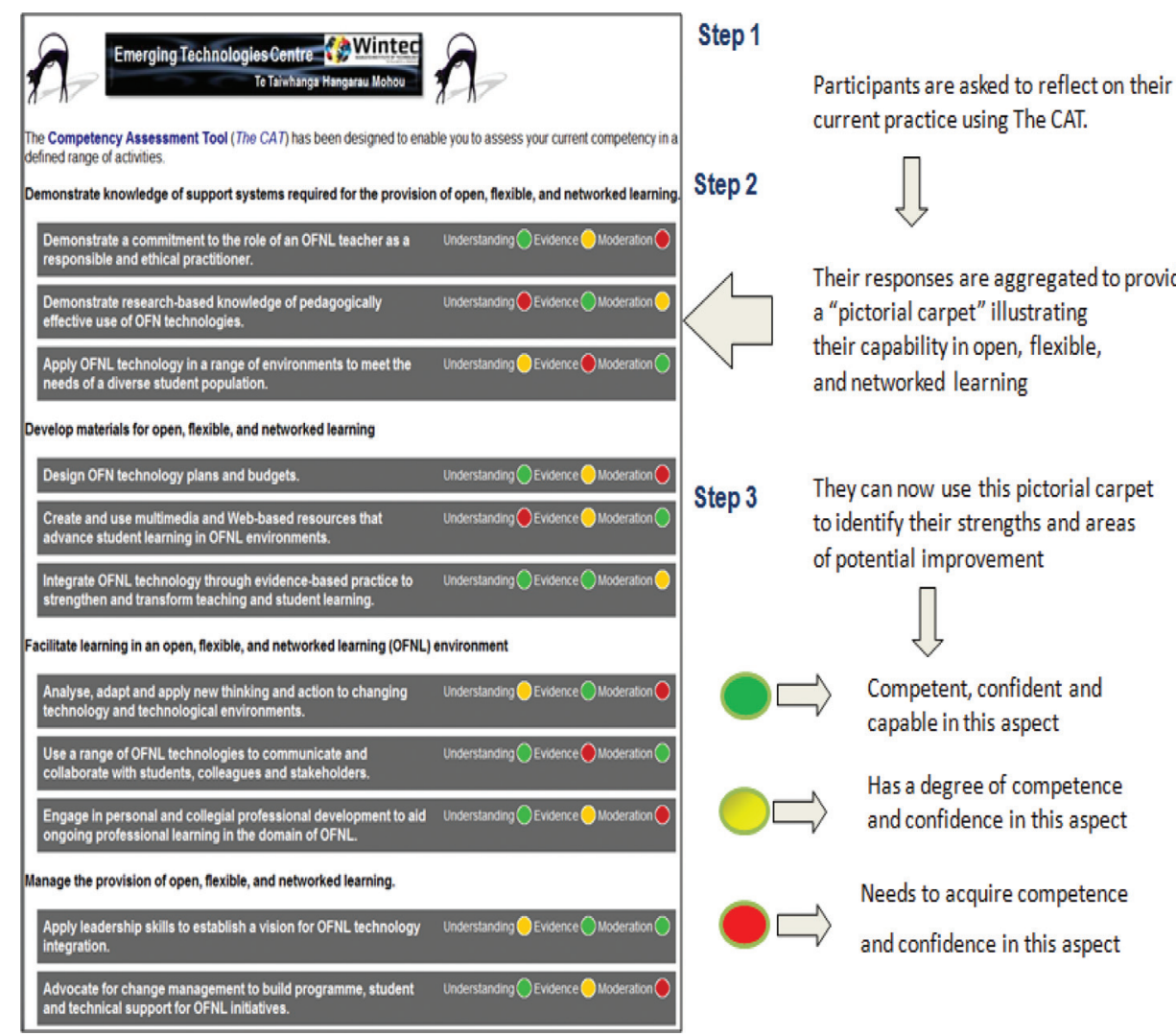

Figure 4. The visual carpet.

\subsection{The supervised mode}

Whilst designing individualised personal learning plans are focused on enabling the individual to take ownership of the learning process, the regulations of COFNL recognise individuals cannot achieve their intended professional goals in isolation. When the participant enrols in the certificate they are allocated a mentor. The mentor will use the results of the CAT and generated learning plan to guide learners by providing appropriate links to educational theory and practical demonstrations. However, mentorship is not a one-way process. COFNL identifies both the responsibilities of the mentor and learner. The responsibilities of the mentor include:

- Being available at predetermined times throughout the duration of the learners' enrolment in the course.

- Providing ongoing guidance, encouragement and support, and assist students to achieve their identified learning outcomes.

- Ensuring learners' receive timely and appropriate feedback on course progress and on outcomes of specific requests.

- Monitoring the individual learner to ensure completion of a comprehensive record of achievement in a personal online e-portfolio. 
The responsibilities of the learner include

- Acting in an ethical and responsible way in all communications associated with the course.

- Submitting evidence of achievement of individual outcomes on a regular basis.

- Submitting evidence of achievement of learning outcomes in the format outlined by their mentor.

- Abiding by any response timeframe set by mentors to ensure appropriate and timely feedback is received.

\subsection{Digital portfolios}

In accreditation environments like COFNL, digital portfolios can provide a protected space where learner evidence of competencies can be rigorously controlled and systematically evaluated. In COFNL learners are shown how to structure their portfolio around the assessment rubric created for each of the five modules. The assessment rubric provides a measure of quality of performance based on established practice in open, flexible and networked learning environments as identified by the New Zealand Qualifications Authority (NZQA). In essence the rubric is based upon what the participant can demonstrate they have learnt, rather than what has been taught. As such it should be regarded as an authentic CAT. Crucially the evidence provided will be the learners' own creation showing how their experiences have met the identified standard. An example of this structure is illustrated in Table 1.

\section{Review and discussion}

This paper has argued that the growing need for higher education institutions to remain financially viable, globally competitive and internationally relevant has motivated them to aggressively market their educational course offerings (Barboza 2011). As a consequence institutions are becoming increasingly socially diverse and multi-cultural. The need for educators to interact with diverse students and to manage cultural differences effectively becomes significant (Sawir 2011). Simultaneously, the demand for flexibility, the implementation of learning management systems and the increased access to ICT infrastructures mean that educators are now actively encouraged to engage with increased numbers of distributed and diverse learners in often unfamiliar ICT-based learning environments (OECD 2005). There appears to be an unstated expectation educators will be able to design learning modules to meet multi-cultural student needs, in a range of contexts, with the same

Table 1. Portfolio structure.

Main category $\quad$ Sub-category

Demonstrate knowledge of theoretical Apply sound knowledge and understanding of adult models of adult learning learning theories and epistemological principles to the effective design of learning objectives, curriculum and application of OFNL technologies in learning and teaching

Contribute to the development of the knowledge base of the OFNL community 


\section{J. Clayton}

resources as before - or less. In essence it is anticipated that diverse learners will participate in flexible learning events, individually customised to meet their specific learning needs, at a cost similar to conventional delivery (New Zealand Treasury 2011). This expectation requires a fundamental shift in educators' and learners' conceptions of the provision of education. The traditional parameters of time, place and pace are challenged as educators begin to mass-customise learning modules.

Mass-customisation fundamentally alters perceptions of educational delivery. The traditional pattern of subject discipline experts creating logically structured and sequenced learning events specifically addressing the knowledge deficiencies of a predetermined number of identified participants is neither flexible enough to meet divergent needs of multiple participants nor economically sustainable (Spanier 2010). To some, mass-customised environments consist of identified modularised learning objects provided efficiently and effectively to limitless numbers of participants' ondemand (Cohen and Pine 2007). However, this rudimentary approach, which fails to acknowledge learners' existing knowledge, their previous learning experiences, their current level of skill, their economic and/or cultural background or learning style, encourages a surface level of processing where the impact of the learning event is often limited to the reproduction of knowledge (Mimirinis and Bhattacharya 2007). For deep learning to occur the design and implementation of mass-customised curricula should ultimately create learning environments that challenge students to meaningfully reflect on their existing knowledge, level of skill and their learning experience (Ghaye 2011). This design process involves the creation of reflective frameworks, based upon an industry-accepted assessment rubrics, which learners use to reflect on their current competencies and identify the critical gaps they need to address.

While a mass-customised approach to educational delivery provides, firstly, institutions with the agility to respond to divergent learner needs and, secondly, empowers individuals to develop personal learning plans ensuring they take ownership of their own learning, institutions should mass-customise their course offerings with care. It appears that the use of learner-centred reflective frameworks would allow the automation of a process determining the construction and delivery of individualised learning modules and the appointment of a mentor. This part-human, partautomated process model, following pre-determined rules, involves four identified actors (learners, mentors, designers and assessors), actively engaging with each other in a common virtual space. This approach enables learners to both make meaning from their learning experiences and provides them with the reflective skills to be lifelong learners. This approach to the mass-customisation allows institutions to extend their reach and educators to broaden their repertoire of teaching skills. This improves not only the quality and relevance of courses offered but also the experiences of learners.

\section{Summary}

Mass-customisation shows potential in the creation of cost-effective, learningcentric higher educational environments, and this has become increasingly relevant in times of fiscal restraint. The automated construction of individualised learning plans, the evolution of this automated process and the impact of automation on the learning experiences of individuals needs to be further examined. Research needs to be undertaken to provide evidence regarding the impact and effect of masscustomisation, driven by reflection, on learners, educators and institutions. 


\section{References}

Barboza, D. (2011) 'Berkeley has plan to start a program in Shanghai': [Foreign Desk]. New York Times, 8 Dec., from Banking Information Source, (Document ID: 2513038291).

Carlson, T. \& Parry, S. (2003) 'A reflective framework from a pre-service teacher's perspective', Physical Educator, vol. 60, no. 4, pp. 208-221.

Ciorba, C. \& Smith, N. (2009) 'Measurement of instrumental and vocal undergraduate performance juries using a multidimensional assessment rubric', Journal of Research in Music Education, vol. 57, no. 1, pp. 5-15.

Clayton, J. (2009) Evaluating online learning environments, LAP Lambert Academic Publishing, Köln.

Clayton, J. (2011) 'Reflective-frameworks and international education: rethinking, teaching, learning and the curriculum: a case study', Cambridge International Conference on Open, Distance and e-Learning: Internationalisation and Social Justice: the role of Open, Distance and e-Learning: Collected Conference Papers and Abstracts: September 2011. The Von Hügel Institute, St Edmund's College, Cambridge, in association with The Open University and The Commonwealth of Learning, Cambridge, pp. 74-85.

Clayton, J., Elliott, R. \& Saravani, S.-J. (2009) ICT PD Cluster Programme Research Review Project: Report on Key Recommendations, Trends, and Lessons from ICT PD Provision, Project Report, Emerging Technologies Centre, Hamilton.

Cohen, S. L. \& Pine, B. J. (2007) 'Mass customizing the training industry', Training and Development, vol. 61, no. 6, pp. 50-54.

Cross, R. et al. (2009) 'Design communication for mass-customisation', International Journal of Mass-Customisation, vol. 3, no. 2, pp. 146-164.

Fiedler, R. L., Mullen, L. \& Finnegan, M. (2009) 'Portfolios in context: a comparative Study in two pre-service teacher education programs', Journal of Research on Technology in Education, vol. 42, no. 2, pp. 99-122.

Gaeta, A., Gaeta, M. \& Ritrovato, P. (2009) 'A grid based software architecture for delivery of adaptive and personalised learning experiences', Personal and Ubiquitous Computing, vol. 13 , no. 3, pp. 207-217.

Ghaye, T. (2011) Teaching and Learning through Reflective Practice: A Practical Guide for Positive Action, Routledge, Abingdon, Oxon.

Hwang, G., Tseng, J. \& Hwang, G. (2008) 'Diagnosing student learning problems based on historical assessment records', Innovations in Education and Teaching International, vol. 45, no. 1 , pp. $77-89$.

Kerby, D. \& Romine, J. (2010) 'Develop oral presentation skills through accounting curriculum design and course-embedded assessment', Journal of Education for Business, vol. 85, no. 3, pp. 172-179.

Kieke, M., Moroz, K. \& Gort, A. (2007) 'The transformation to a learner-centered community as a result of university-wide assessment', On the Horizon, vol. 15, no. 2, pp. 107-117.

Kim, P., Ng, C. \& Lim, G. (2010) 'When cloud computing meets with semantic web: a new design for e-portfolio systems in the social media era', British Journal of Educational Technology, vol. 41, no. 6, pp. 1018-1028.

Korthagen, F. \& Vasalos, A. (2005) 'Levels in reflection: core reflection as a means to enhance professional growth', Teachers and Teaching, vol. 11, no. 1, pp. 47-71.

Latimer, M., Bergee, M. \& Cohen, M. (2010) 'Reliability and perceived pedagogical utility of a weighted music performance assessment rubric', Journal of Research in Music Education, vol. 58 , no. 2, pp. $168-183$.

Martinez, L. (2011) 'The study abroad advantage', Diverse Issues in Higher Education, vol. 28, no. 19 , pp. 25.

McColgan, K. \& Blackwood, B. (2009) 'A systematic review protocol on the use of teaching portfolios for educators in further and higher education', Journal of Advanced Nursing, vol. 65 , no. 12 , pp. $2500-2507$.

Mimirinis, M. \& Bhattacharya, M. (2007) 'Design of virtual learning environments for deep learning', Journal of Interactive Learning Research, vol. 18, no. 1, pp. 55-64.

New Zealand Ministry of Education. (2010) Tertiary Education Strategy 2010-15, New Zealand Government, Wellington.

New Zealand Treasury. (2011) 'Performance information for appropriations: vote tertiary education', Education and Science Sector: Information Supporting the Estimates 2011/12 


\section{J. Clayton}

B.5A Vol. 2, Wellington, New Zealand, Available at: http://www.treasury.govt.nz/budget/ 2011/ise/v2/ise11-v2-pia-tered.pdf

New Zealand National Qualifications Authority: NZQA. (2011) 'Domain - Open, Flexible, and Networked Learning', Retrieved 23 March 2012 from http://www.nzqa.govt.nz/ framework/explore/domain.do?frameworkId=1263616601

Organization for Economic Co-Operation and Development (OECD). (2005) 'E-learning in tertiary education', Policy Briefs, Available at: http://www.oecd.org/dataoecd/27/35/ 35991871.pdf

Penner, R. (2001) 'Mentoring in higher education', Direction, vol. 30, no. 1, pp. 45-52.

Peter, S., Bacon, E. \& Dastbaz, M. (2010) 'Adaptable, personalised e-learning incorporating learning styles', Campus-Wide Information Systems, vol. 27, no. 2, pp. 91-100.

Sawir, E. (2011) 'Academic staff response to international students and internationalising the curriculum: the impact of disciplinary differences', International Journal for Academic Development, vol. 16 , no. 1 , pp. 45-57.

Spanier, G. B. (2010) 'Creating adaptable universities', Innovative Higher Education, vol. 35, no. 2 , pp. $91-99$.

Strudler, N. (2011) 'Electronic portfolios in teacher education: forging a middle ground', Journal of Research on Technology in Education, vol. 44, no. 2, pp. 161.

Syed-Khuzzan, S. \& Goulding, J. (2009) 'Personalised learning environments (part 2): a conceptual model for construction', Industrial and Commercial Training, vol. 41, no. 1, pp. $47-56$.

Syed-Khuzzan, S., Goulding, J. \& Underwood, J. (2008) 'Personalised learning environments part 1: core development issues for construction', Industrial and Commercial Training, vol. 40, no. 6, pp. 310-319.

Turner, F. (2009) 'The Influence of mass-customisation on consumer satisfaction and its implications for the U.S. IPTV television market: an exploratory study', Business Leadership Review, vol. 6, no. 4 [Electronic Version], Available at: http://www.mbaworld. com/blr-archive/issues-64/4/index.pdf

Verdouw, C. et al. (2010) 'Towards dynamic reference information models: readiness for ICT mass-customisation', Computers in Industry, vol. 61, no. 9, pp. 833-844.

Xia, S.-S. \& Wang, L.-Y. (2010) 'Customer requirements mapping method based on association rules mining for mass-customisation', International Journal Computer Applications in Technology, vol. 37, no. 3/4, pp. 198-203.

Zimmerman, B. (1990) 'Self-regulated learning and academic achievement: an overview', Educational Psychologist, vol. 25, no. 1, pp. 3-17. 